Article

\title{
Modeling the Liberation of Comminuted Scheelite Using Mineralogical Properties
}

\author{
Sarbast Ahmad Hamid ${ }^{1, *(\mathbb{D})}$, Pura Alfonso ${ }^{1} \mathbb{D}$, Josep Oliva ${ }^{1}$, Hernan Anticoi ${ }^{1}{ }^{1}$, \\ Eduard Guasch ${ }^{1} \oplus$, Carlos Hoffmann Sampaio ${ }^{1}$, Maite Garcia-Vallès ${ }^{2} \oplus$ and Teresa Escobet ${ }^{1}$ \\ 1 Departament d'Enginyeria Minera, Industrial i TIC, Universitat Politècnica de Catalunya Barcelona Tech, \\ Av. Bases de Manresa 61-63, 08242 Manresa, Barcelona, Spain \\ 2 Departament de Mineralogia Petrologia i Geología Aplicada, Universitat de Barcelona, Carrer Martí i \\ Franquès, s/n, 08028 Barcelona, Spain \\ * Correspondence: sarbast.hamid@upc.edu; Tel.: +34-9877-7244
}

Received: 20 July 2019; Accepted: 30 August 2019; Published: 3 September 2019

\begin{abstract}
In this paper, the modeling of the liberation of scheelite is presented. A pattern of concentration experiments was performed to investigate the scheelite liberation and distribution density calculation procedure. In this work, one sample from a Mittersill tungsten ore was studied. This work describes a method for determining the downstream milling energy requirements for rod mill products based on a Bond mill test performance. The grade distribution of particles at a given size fraction was calculated using a predictive liberation model. The concentration behavior of these particles in size fractions was evaluated using batch concentrate tests. The recovery of particles in size/grade classes, image analysis using mineral liberation analysis (MLA), and function calculations were implemented for the modeling of the liberation. By describing the size, grade, and recovery data of particles in size/grade classes, a technique for the measurement of distribution functions was developed that relates beta distribution, a model for the function based on the incomplete beta function, and a solution to produce liberation modeling. It was shown that the predicted results agreed well with the observed results. With a procedure for measuring the liberation, it was possible to carry out the first experimental measurement of the beta distribution. This liberation/concentrate model has wide potential applications for metallurgy and plant design, where the liberation modeling is to be determined with the distribution density solution to the predictive mineral liberation function equation, which includes the liberation of ore samples and their liberation characteristics.
\end{abstract}

Keywords: scheelite; MLA; beta distribution; liberation modeling

\section{Introduction}

Tungsten is considered as a critical raw material due to its economic importance, high supply risk, the lack of efficient substitutes, and low recycling rates [1]. Tungsten has a wide range of applications in industry, such as high-temperature technology, the chemical industry, lighting, X-ray technology, and superalloys [2]. Tungsten's properties, such as its low vapor pressure, high melting point, good electrical and thermal conductivities, high density, high elastic modulus, high wear resistance, and good X-ray performance, have made these applications possible [3,4]. More than $83 \%$ of the world's tungsten production occurs in China and only 3.1\% occurs in Europe [5]. Statistics reveal that tungsten is a critical metal for the European Union (EU), as well as for the US Department of Defense and for the government of the Russian Federation [6].

Several mines have been opened during the last decade in the EU; however, a bigger production is still necessary [7]. Therefore, the exploitation of low-grade deposits could be of interest, and new methods that optimize mineral processing have to be found. Mineral liberation from the gangue 
determines the efficiency of subsequent separation processes [8] and should be accurately investigated. This is even more important when it comes to scheelite, as it often associated with Ca-bearing minerals in skarn ores, which are problematic during flotation as they have the same surface properties as scheelite [9].

The liberation characteristics of an ore are primarily dependent on its texture; on the association of the mineral in the host matrix of gangue minerals; and, to some extent, on the grinding process [8]. Furthermore, the success of a comminution process depends on the achieved liberation. The measurement of liberation data can be precisely obtained by quantitative mineralogical methods by using scanning electron microscopy coupled with an energy dispersive analyzer and a database [10,11], followed by models that predict the mineral liberation obtained during comminution [12,13]. Mineral liberation analysis (MLA) is a useful technique for obtaining most data to complete liberation characterization $[14,15]$.

The main tungsten minerals exploited for primary tungsten extraction are scheelite $\left(\mathrm{CaWO}_{4}\right)$ and wolframite $\left((\mathrm{Fe}, \mathrm{Mn}) \mathrm{WO}_{4}\right)$, which is a member of a solid solution comprised of hubnerite $\left(\mathrm{MnWO}_{4}\right)$ and ferberite $\left(\mathrm{FeWO}_{4}\right)$. Approximately two thirds of the world's tungsten reserves consist of skarn deposits [16-18].

King [19] developed a predictive liberation model based on the mineral grade distribution of valuable and gangue minerals when describing a population of particles produced during the grinding process. The results from this study showed that the fraction of fully liberated mineral, $L_{1}(x)$, and gangue $L_{0}(x)$ particles produced by random breakage could be estimated from Equations (1) and (2):

$$
\begin{aligned}
& L_{1}(x)=\frac{\mu_{1}}{\mu_{0}+\mu_{1}} e^{-\frac{x}{\mu_{1}}} \\
& L_{0}(x)=\frac{\mu_{0}}{\mu_{0}+\mu_{1}} e^{-\frac{x}{\mu_{0}}}
\end{aligned}
$$

where $x$ is the size of a particle produced from two successive random cuts made on a plane section of the parent rock. $\mu_{1}$ and $\mu_{0}$ are the mean mineral and gangue intercept lengths, respectively.

King [20] proposed a theory that was completely free of empirical constants or other parameters. The theory predicts that the fractional liberation of a mineral at mesh size $D$ is given by Equation (3):

$$
L(D)=1-\frac{1}{\mu} \int_{0}^{D_{u}}\{1-N(l \mid D)\}\{2-F(l)\} d l
$$

where $F(l)$ is the distribution of linear intercept lengths for the mineral and $\mu$ is the mean linear intercept length for the mineral. $N(l \mid D)$ is the linear intercept distribution function for particles of mesh size $D$, and $D_{u}$ is the largest intercept length across any particle of mesh size $D$.

Schaap [21] extended this model, including the compound particles and liberated particles produced during random breakage.

A liberation model based on the texture of the parent rock has been described by Barbery [22] and by Barbery and Leroux [23]. Barbery [22] estimated the distributions of the covariance function and proximity function based on the particle structure and ore texture, i.e., the distribution of valuable mineral and gangue within the parent rock.

Several models have been developed to describe the liberation properties of mineral particles, including the liberation characteristics, in predicting the downstream separation process by using the texture and grade distribution of low-grade ores [21,24].

Barbery and King [22,25] developed a beta distribution function with parameters $\alpha$ and $\beta$ to describe the shape of the valuable and gangue minerals. This is only an approximation of the distribution measurements and has been shown to be generally applicable for low- and high-grade ores. It has also been assumed that the model may be extended to composite ores of valuable minerals and 
gangue. This distribution function was developed [25] for a description of the populations of particles that have a variable mineral content. This distribution function is based on the beta distribution that is widely used in mathematical statistics and can be estimated from Equation (4):

$$
P(\mathrm{~g})=\left(1-L_{0}-L_{1}\right) \frac{g^{\alpha-1}(1-g)^{\beta-1}}{B(\alpha, \beta)} \quad 0<g<1
$$

where $g$ is the average grade of the particle produced from random grinding made on a plane section of the parent rock, $\alpha$ and $\beta$ are the distribution parameters, and $B(\alpha, \beta)$ is the distribution function.

Zhang [26] measured the linear intercept grade distribution of valuable and gangue minerals. He found that the particle breakage that may have occurred during the grinding process provided a better fit to simulated data in different size classes (e.g., $300 \mu \mathrm{m}$ and $800 \mu \mathrm{m}$ ).

Zhang and Subasinghe [8,27] proposed a comparison mainly based on liberated particles by the use of a binary ore. They developed a liberation model and a grade distribution of the comminuted particles from linear measurements.

This work determines the mineral liberation modeling of a scheelite ore from a processing plant, using quantitative mineralogy and simulation to complete the characterization. The liberation modeling was obtained using a back-calculation method in MATLAB with the grade/size distribution to produce a predictive liberation model.

\section{Materials and Methods}

\subsection{Materials}

The scheelite sample used in this study consisted of crushed ore from the processing plant of a Mittersill tungsten mine in Austria. The ore consisted of scheelite associated with calc-silicate minerals. Scheelite is exploited from veins hosted in an amphibolite rock mainly composed of quartz, plagioclase (albite), hornblende, actinolite, and K-feldspar, with biotite, muscovite, and epidote as minor minerals.

The feed material, with a top size of $13 \mathrm{~mm}$, was comminuted in a jaw crusher to obtain a $-1 \mathrm{~mm}$ size fraction. The samples were placed in a laboratory rod mill at 46 RPM. It should be emphasized that the laboratory tests were carried out under repeatable and controlled conditions. The milled sample was separated into two target product size distributions: 'fine' ( $80 \%$ passing $250 \mu \mathrm{m})$ and 'coarse' $(20 \%$ passing 250-600 $\mu \mathrm{m}$ ).

Anticoi [28] considered that most scheelite of a Mittersill ore occurs in the fine fractions. With this finding from previous studies, the ore was ground smaller than $250 \mu \mathrm{m}$. Finally, scheelite was physically concentrated in a shaking table (Figure 1).

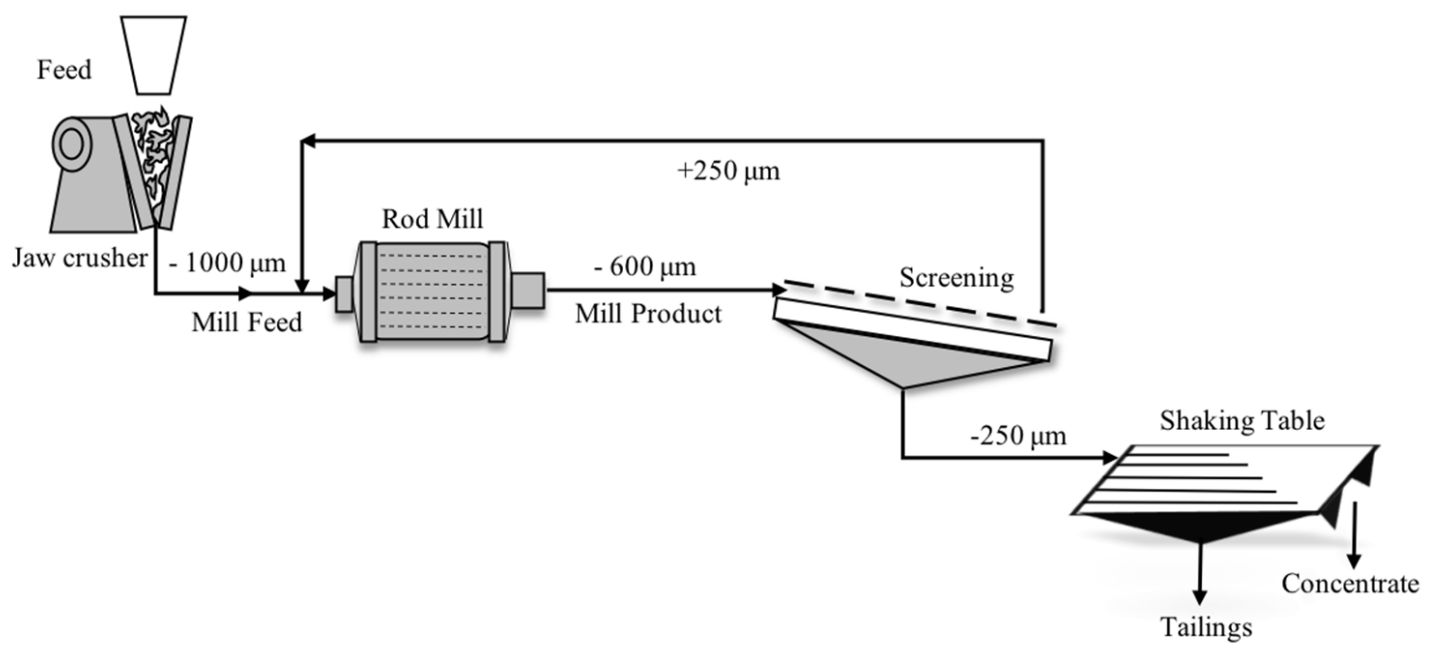

Figure 1. Schematic diagram of the work conducted in the laboratory. 
To reach the liberation size, the sample and steel rods were loaded into the rod mill, and a dry grinding test was run. The milled material was sieved at $250 \mu \mathrm{m}$, and the non-passing fraction was added to the feed material in the rod mill for different time intervals (4,6, and $8 \mathrm{~min})$. For each stage, milled material with a $+250 \mu \mathrm{m}$ size fraction was combined with the rest of the mill discharge as the feed for the next grinding interval. The passing fractions $(-250 \mu \mathrm{m})$ were all used in the shaking table feed (Figure 1). The mill specifications and operating conditions are presented in Table 1.

Table 1. Specifications for laboratory rod mill operating.

\begin{tabular}{ccc}
\hline Specification & Unit & Test \\
\hline Feed graded charge & $\mathrm{mm}$ & 13.2 \\
Total media mass & $\mathrm{kg}$ & 9530 \\
Mass of ore sample & $\mathrm{kg}$ & 2.680 \\
Dried bulk density & $\mathrm{g} / \mathrm{cm}^{3}$ & 1.90 \\
Mill speed & $\mathrm{rpm}$ & 46 \\
Mill length & $\mathrm{mm}$ & 610 \\
Mill diameter & $\mathrm{mm}$ & 305 \\
Power drawn & $\mathrm{W}$ & 255 \\
Unload power & $\mathrm{W}$ & 201 \\
Net power & $\mathrm{W}$ & 54 \\
Milling time & $\mathrm{m}$ & 18 \\
Specific energy intensity $(-600 \mu \mathrm{m})$ & $\mathrm{kWh} / \mathrm{t}$ & 1.46 \\
Specific energy intensity $(-250 \mu \mathrm{m})$ & $\mathrm{kWh} / \mathrm{t}$ & 3.94 \\
\hline
\end{tabular}

\subsection{Work Index Test}

To determine the power consumed by the rod mill, a Power Logger was used, based on measurements of current and potential difference. To estimate the energy efficiency of the rod mill, the unload power and power drawn over the entire grinding period were used, when the mill was stable and when the mill started, during the entire grinding period. The energy required to generate new material finer than $250 \mu \mathrm{m}$ was calculated as the size-specific energy intensity (Table 1). The feed and product particle size distributions are presented in Section 3.3, along with the bulk mineralogy of the ore.

The standard Bond's test includes a batch dry grinding of the sample, which is carried out in a standard test mill and operated in a closed-circuit grinding operation with a recirculating load. The rod charge consists of eight rods, weighing approximately $33.38 \mathrm{~kg}$, which are $533 \mathrm{~mm}$ in length. The test is performed at a grinding size that, ideally, should be the industrial grinding size. In this case, the grindability test was performed for mineral characterization, and four sizes $(45,75,125$, and $250 \mu \mathrm{m})$ were selected to perform the tests. Once these values were determined, the grindability function was used to calculate the work index value at each size within the size ranges tested. The feed was prepared under $13.2 \mathrm{~mm}$, and an adequate sample reduction was carried out. The material was packed to $1250 \mathrm{~cm}^{3}$ volume manually. The weight of this volume was charged to the mill. The mill was operated for 30 revolutions, using a dried screen to remove undersized particles and then replace the undersized material with new feed. The procedure was repeated until the mass of the circulating material was equal to the new feed provided to the closed circuit or the screen undersized material, at a steady state [29]. With proper feed, this equilibrium condition may be reached in 6-8 grinding cycles. After reaching the equilibrium value, an average of the grindabilities $\left(G_{r p}\right)$ was calculated for the last three cycles. The average value was taken as the standard Bond ore grindability to calculate the work index at each selected size. In the current work, standard Bond's test protocols were performed, and a 
complete description of the test may be found elsewhere [30-33]. The laboratory work index test gives the standard work index (Wi), which is calculated from Equation (5) [34]:

$$
W_{i}=\frac{68.2}{A^{0.23} G_{r p} 0.625\left(\frac{10}{\sqrt{P_{80}}}-\frac{10}{\sqrt{F_{80}}}\right)}
$$

where $F_{80}$ and $P_{80}$ are the $80 \%$ passing size $(\mu \mathrm{m})$ of the mill new feed and circuit product, respectively; $A$ is the test-sieve size used $(\mu \mathrm{m})$; and $G_{r p}$ is the mass of the undersized product per mill revolution $(\mathrm{g} / \mathrm{rev})$.

\subsection{Analytical Methods}

The chemical composition of the original and processed samples was obtained at the ALS laboratory Group, where W was measured using inductively coupled plasma mass spectrometry (ICP-MS) from the acid digestion of fused glass beads. Mineralogy was determined by X-ray powder diffraction (XRD), scanning electron microscopy (SEM), and mineral liberation analysis (MLA). The XRD spectra were measured from powdered samples in a Bragg-Brentano PANAnalytical X'Pert Diffractometer (graphite monochromator, automatic gap, $\mathrm{K} \alpha$-radiation of $\mathrm{Cu}$ at $\lambda=1.54061 \AA$, powered at $45 \mathrm{kV}-40 \mathrm{~mA}$, scanning range $4-100^{\circ}$ with a $0.017^{\circ} 2 \theta$ step scan and a 50 -s measuring time). The identification and Rietveld semiquantitative evaluation of phases were conducted on PANanalytical X'Pert HighScore software (Version 2.0.1, PANanalytical, Almelo, The Netherlands).

Textures were observed by optical and electronic microscopy. The equipment was a Hitachi 1000 tabletop electron microscope with an energy-dispersive X-Ray spectrometer (EDX, High-Technologies Corporation, Tokyo, Japan).

MLA was used to quantify the bulk mineralogy, grain size, particle size distribution grinding, mineral liberation, and associations. The MLA analysis was carried out at the University of Tasmania using an FEI MLA 650 ESEM (FEI, Hilsboro, OR, USA). Representative samples were prepared using different sized fractions after concentration. MLA measurements were performed at $20 \mathrm{kV}$ with a 1.5- $\mu \mathrm{m}$ pixel resolution using the X-ray Backscattered Electron (XBSE) method, which collects a range of Backscattered Electron (BSE) images at a specified resolution, segments the images into different mineral grains based on BSE contrast and textural features, and collects a single energy-dispersive (ED) spectrum for each identified mineral grain.

In this work, a combination of X-ray diffraction (XRD) and mineral liberation analysis (MLA) was used to investigate problems and find possible solutions for the quantitative mineralogical characterization of scheelite. These two analytical methods that were applied are largely supplementary. Minerals are identified by the properties of their crystal structure by XRD, whilst MLA analysis relies on their compositional contrast with other minerals. The results of quantitative X-ray powder diffractometry (QXRD) by multiphase Rietveld refinement $[35,36]$ can be highly accurate and allow the quantification of the abundance of minerals present, down to $0.5 \mathrm{wt} . \%$, in representative powder samples $[37,38]$.

\section{Results and Discussion}

\subsection{Chemical Composition}

To determine impurities in the mineral samples, chemical analyses were performed [39]. The chemical composition of the whole sample is presented in Table 2. In the sample, the high content of $\mathrm{MgO}, \mathrm{FeO}$, and $\mathrm{CaO}$ is indicative that tungsten is associated with calc-silicate rocks.

Table 2. Chemical composition of the sample.

\begin{tabular}{cccccccccccccc}
\hline Oxides & $\mathrm{SiO}_{2}$ & $\mathrm{Al}_{2} \mathrm{O}_{3}$ & $\mathrm{MnO}$ & $\mathrm{TiO}_{2}$ & $\mathrm{FeO}$ & $\mathrm{MgO}$ & $\mathrm{CaO}$ & $\mathrm{Na}_{2} \mathrm{O}$ & $\mathrm{K}_{2} \mathrm{O}$ & $\mathbf{M n O}$ & $\mathrm{P}_{2} \mathrm{O}_{5}$ & LOI & Total \\
\hline Content (wt.\%) & 59.30 & 12.25 & 0.14 & 0.74 & 6.96 & 5.94 & 7.17 & 2.77 & 1.30 & 0.79 & 0.09 & 1.55 & 99.00 \\
\hline
\end{tabular}


Scheelite was analyzed through an inductively coupled plasma mass spectrometer (ICP-MS). The $\mathrm{W}$ content is $2260 \mathrm{ppm}$, which indicates a medium-grade deposit. It also contains $7.17 \% \mathrm{CaO}, 59.30 \%$ $\mathrm{SiO}_{2}$, and $12.25 \% \mathrm{Al}_{2} \mathrm{O}_{3}$. The chemical analysis of scheelite content for the concentrate and tailings material that resulted from physical separation is $3.52 \%$ and $0.13 \%$, respectively.

\subsection{Mineral Association}

A combination of XRD and MLA analyses enabled a successful identification and assessment of the mineralogical composition of the scheelite sample. Overall, 55 minerals were identified.

The averaged results of XRD and MLA measurements in the feed, concentrate, and tailings are presented in direct comparison (Table 3). The sample contained a similar concentrate and tailings of minerals to hornblende and titanite. The actinolite and plagioclase mineral content was highly variable. Expectedly, quartz concentrations above $17 \mathrm{wt} . \%$ were found in tailings, and about $7 \mathrm{wt} . \%$ concentrate minerals were found in the ore.

Table 3. Modal mineralogy of the whole sample, concentrate, and tailings determined by X-ray powder diffraction (XRD) and mineral liberation analysis (MLA).

\begin{tabular}{ccccccc}
\hline \multirow{2}{*}{ Mineral (wt.\%) } & Density & \multicolumn{3}{c}{ XRD } & \multicolumn{2}{c}{ MLA } \\
\cline { 3 - 6 } & & Ore & Tailings & Concentrate & Tailings & Concentrate \\
\hline Scheelite & 6.01 & 0.35 & 0.20 & 17.01 & 0.85 & 17.82 \\
Quartz & 2.62 & 15.30 & 15.37 & 6.74 & 17.13 & 7.50 \\
Plagioclase & 2.68 & 22.30 & 22.42 & 7.90 & 28.27 & 8.39 \\
K-feldspar & 2.56 & 4.50 & 4.54 & 0.51 & 2.87 & 0.49 \\
Hornblende & 3.23 & 33.00 & 27.95 & 20.79 & 28.47 & 20.18 \\
Actinolite & 3.04 & 6.40 & 6.24 & 1.00 & - & - \\
Pyroxene & 3.40 & 1.00 & 8.02 & 3.20 & 9.08 & 2.91 \\
Vesuvianite & 3.40 & - & 0.98 & 0.27 & - & 0.22 \\
Epidote & 3.45 & 4.30 & 1.00 & 15.47 & 0.42 & 14.88 \\
Biotite & 3.09 & 7.70 & 5.90 & 2.92 & 6.22 & 1.80 \\
Muscovite & 2.82 & - & 2.15 & 0.30 & 1.76 & 0.28 \\
Chlorite & 2.65 & 4.90 & - & 0.29 & - & 0.41 \\
Titanite & 6.01 & - & 1.63 & 3.50 & 1.51 & 3.64 \\
Fe oxide & 2.62 & - & 0.02 & 0.31 & 0.04 & 0.17 \\
Apatite & 2.68 & - & 0.18 & 0.45 & 0.22 & 0.60 \\
Calcite & 2.56 & - & 1.50 & 0.63 & 1.45 & 0.70 \\
Fluorite & 3.23 & - & 0.02 & 0.04 & 0.02 & 0.04 \\
Fe sulfide & 3.04 & - & 1.10 & 17.35 & 1.06 & 18.20 \\
Chalcopyrite & 3.40 & - & 0.02 & 0.75 & 0.03 & 0.83 \\
Arsenopyrite & 3.40 & - & - & 0.11 & - & 0.13 \\
\hline Total & - & 99.75 & 99.24 & 99.54 & 99.40 & 99.19 \\
\hline
\end{tabular}

Scheelite is the only W-bearing mineral from the studied ore which was reported in MLA and XRD. The observation of the ore under UV light allowed the scheelite grains to be differentiated. All of them exhibit a bluish luminescence, which is typical when this mineral has a low content of molybdenum [40]. Other phyllosilicate minerals such as muscovite occur in minor amounts. Epidote, K-feldspar, and titanite are also present. The gangue mainly comprises quartz, plagioclase, hornblende, pyroxene, and biotite (Table 3).

After this, the gravity concentration of the mineral association from the concentrate and tailings was determined using XRD and MLA. Predictably, low-density minerals are concentrated in the tailings, which are enriched in quartz, plagioclase, biotite, and muscovite. On the contrary, scheelite, sulphide minerals, and epidote are concentrated in the high-density fraction.

The distribution of the hornblende minerals varies. Hornblende is the predominant mineral in the concentrate and tailing in the ore. Titanite and epidote have a relatively high density (6.01 and $3.45 \mathrm{~g} / \mathrm{cm}^{3}$, respectively) and thus are concentrated in the heavy fraction, whereas the quartz 
and plagioclase (albite) content is variable in the tailings and remains in the light fraction. The comparison shows higher scheelite contents detected by MLA in the concentrate and tailings. A higher concentration of hornblende, epidote, and Fe-sulfide was primarily shown in the concentrate by XRD and MLA. Data acquired by XRD also show a lower content of hornblende compared to the MLA data. In the MLA, actinolite was not reported; it was probably identified as a pyroxene phase, and thus its composition is similar to other pyroxenes, such as augite.

SEM images show that in the comminuted sample, a high number of scheelite grains are liberated. In other grains, it is associated with other minerals in binary, ternary, or multi-component particles (Figure 2).
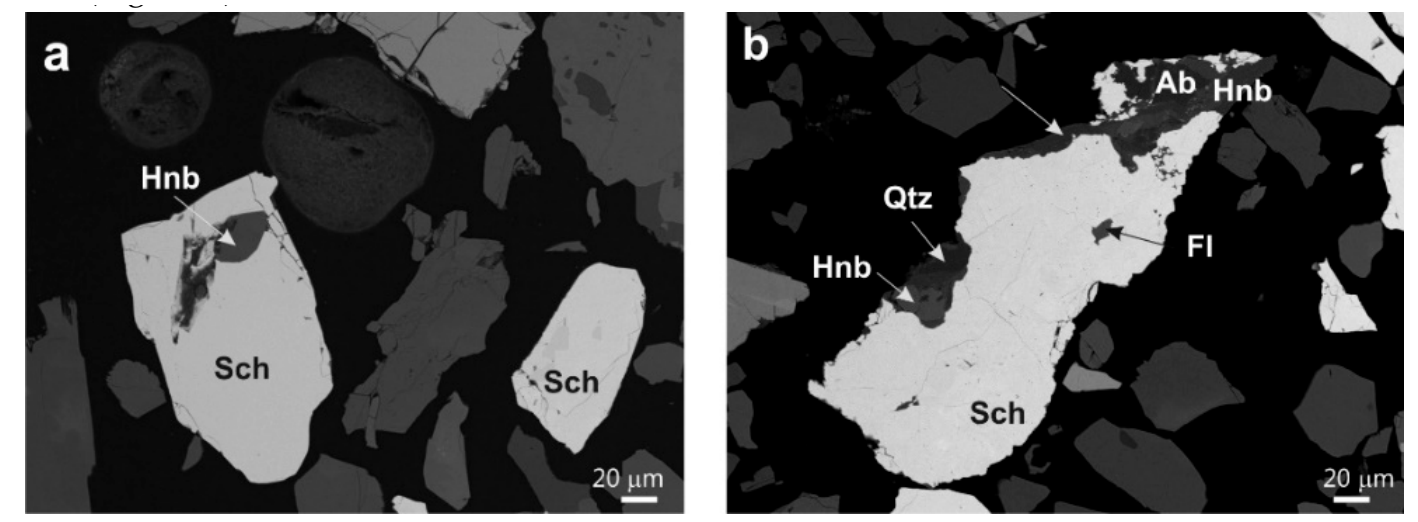

Figure 2. SEM-BSE images of the scheelite concentrate: (a) binary particle of scheelite and hornblende, and (b) multi-component particle. Sch, Scheelite; Hnb, hornblende; Qtz, quartz; Ab, albite; Fl, fluorite.

Figure 3 represents a color image of an area of the MLA of the concentrate sample. The image shows that the mineral association varies considerably according to the particle size fractions. Scheelite and pyrite are more concentrated in the fine fractions (Figure 3). The number of characterized particles in the concentrated and tailing samples was 58,162 and 66,248, respectively. In the most basic liberation analysis method, mineral discrimination is only based on BSE grey level contrast, and the liberation data are generated through image analysis [1]. In the present case, scheelite shows a high contrast with the other possible mineral phases, and it is possible to produce a basic method to calculate the scheelite minerals with a high rate of concentrated scheelite.

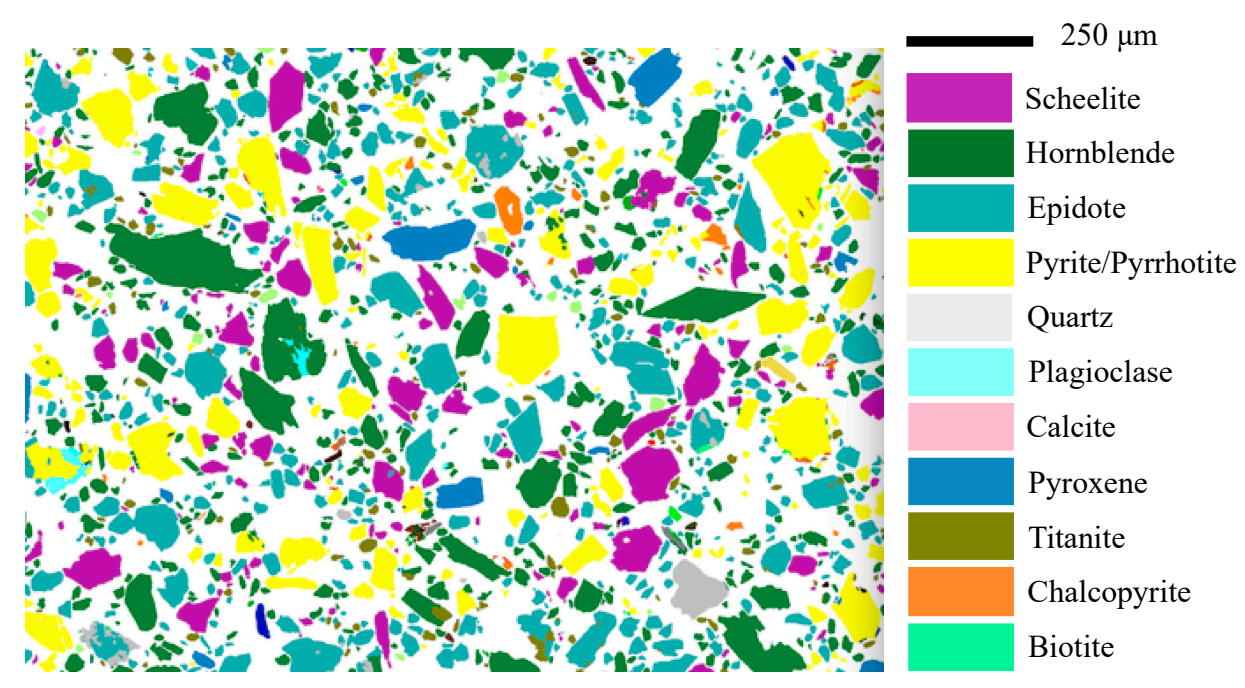

Figure 3. Mineral liberation analysis image showing the characteristics of minerals. 
The liberation characteristics of scheelite in the concentrated sample are shown in Figure 4. More than $87 \mathrm{wt} . \%$ of scheelite is liberated, and about $11.2 \mathrm{wt} . \%$ occurs in binary particles. In most cases, scheelite constitutes particles associated with epidote, quartz, and hornblende (Figure 4).

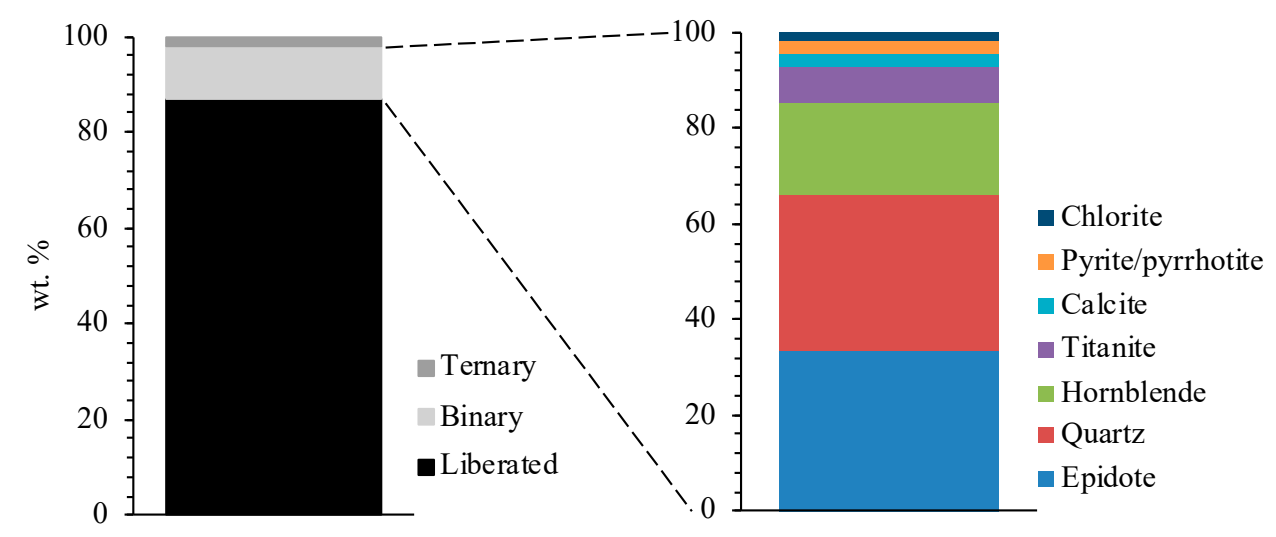

Figure 4. Mineral liberation of scheelite and association of non-liberated scheelite grains.

\subsection{Particle Size Distribution}

The cumulative particle size distributions (PSDs) of the various streams of the flowsheet are shown in Figure 5. For the test work, the PSDs are broad with a shallow slope, although the shaking table feed, feed and mill product sample PSDs are steeper than the feed. About $53 \%$ of the mill material is smaller than $250 \mu \mathrm{m}$, and about $43 \%$ of the milled material in the shaking table feed is smaller than $106 \mu \mathrm{m}$. The measured particle size distribution shows that $80 \%$ of the concentrated material is approximately smaller than $106 \mu \mathrm{m}$. It was found that fine particles are strongly dominant in the shaking table feed data compared to analytical sieving.

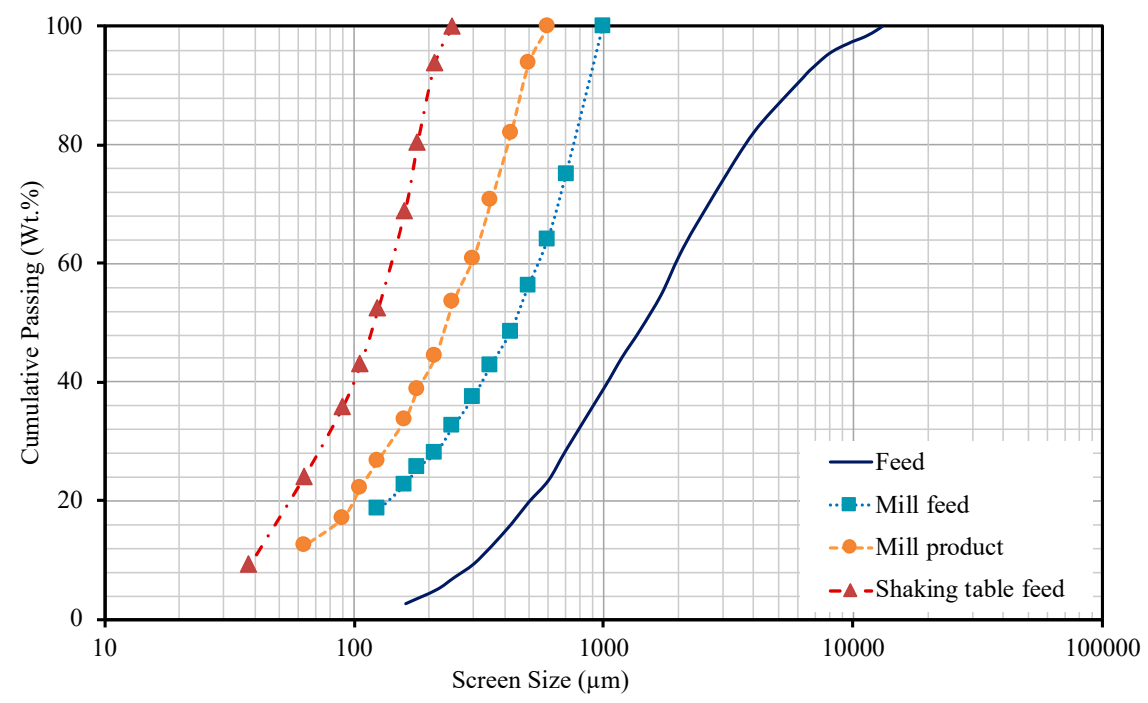

Figure 5. Particle size distribution of the feed, mill product, concentrate, and tailings of the ore sample obtained from gravity separation.

The MLA data provide information on the size of all the measured particles. It is possible to determine the distribution of scheelite in the different particle size fractions and its liberation grade. Scheelite is significantly concentrated in the $-250+106 \mu \mathrm{m}$ size fractions. This is because scheelite grains occur naturally in these grain sizes of the ore deposit. The MLA-estimated scheelite grain size in the gravity concentrate is shown in Figure 6. The average grain size is $106 \mu \mathrm{m}$, and most grains are $<250 \mu \mathrm{m}$. This information, coupled with the findings from the particle size distribution section, indicates that about $20 \%$ of scheelite grains are resistant to grinding and fractures in $\mathrm{W}$-bearing. 
Figure 6 also shows the grain size distribution of the tailings. Almost all grains are $<125 \mu \mathrm{m}$ in the tailings and would require further grinding for sufficient liberation. This would significantly improve the liberation characteristics of scheelite and prove that coarser grinds can achieve sufficiently liberated scheelite. This suggests that coarse complex particles containing scheelite in the tailings are more difficult to grind, which may provide opportunities for concentrations at even coarser particle sizes.

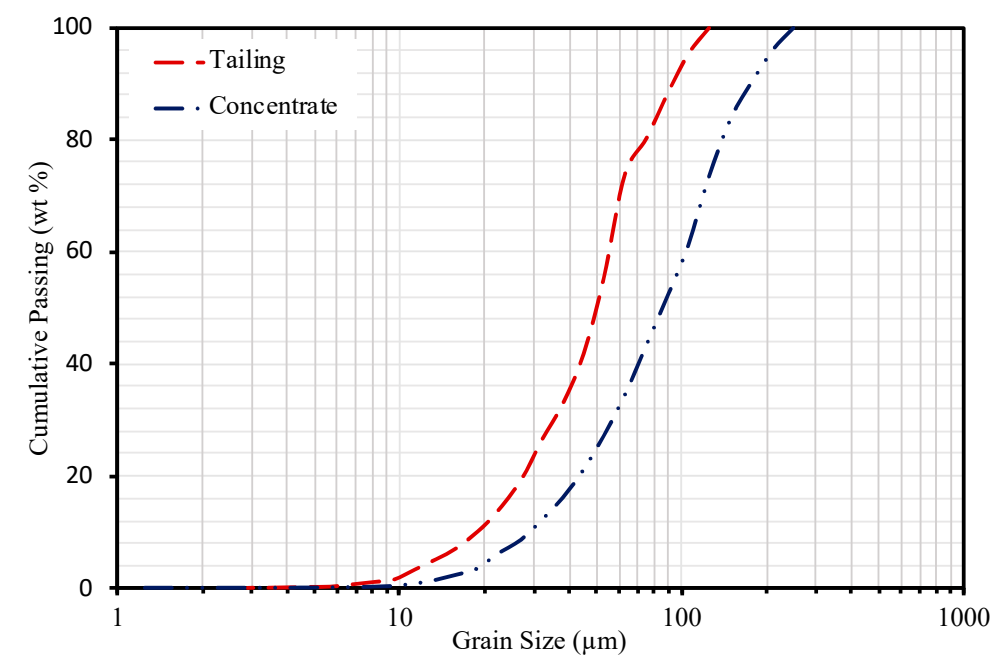

Figure 6. Mineral grain size distribution of scheelite from the sample determined by mineral liberation analysis (MLA).

\subsection{Work Index and Energy Consumption}

The work index of the studied ore ranges from 8.02 to $15.07 \mathrm{kWh} / \mathrm{t}$, according to the particle size of the feed. The increase in the work index indicates a change in the consumed energy of the ore during the grinding. As was seen before, most of the liberated scheelite has a size smaller than $125 \mu \mathrm{m}$, and about $80 \%$ of the liberated scheelite has a size smaller than $110 \mu \mathrm{m}$. This has a negative impact on the milling energy costs. From a size smaller than $125 \mu \mathrm{m}$, with the progress of scheelite liberation production, the increase in the ore work index increases the energy consumption per ton of milled ore. This information helps determine the optimum operational conditions of mineral liberation in order to reduce energy consumption.

In order to evaluate the relationships between the work index and the degree of scheelite liberation in the processed material, the cumulative distribution of the liberated scheelite with the class mean size and the work index is shown in Figure 7. These relationships can be explained by the fact that almost all liberated sheelite is in fine fractions, which causes the work index and energy consumption to increase. The material is a calk-silicate, so scheelite is associated with more than $60 \%$ quartz and epidote (Figure 4). They are the hardest minerals in the material. Therefore, the work index for the deposit ore may be predicted based on the quartz and epidote content of the material [34].

\subsection{Mineral Liberation Modeling}

The concentrate of the gravity separation was selected for the analysis of scheelite liberation. MLA reported data by the sizes and liberation classes of the scheelite mineral, which was finely ground and of a medium grade, and used for the characterization in the flowsheet of this work. Using mineral liberation analysis data, the differential masses of the concentrated material with different grades of scheelite were calculated. Mineralogical characterization was performed by the MLA technique, and the stream samples were sized into 13 size classes from 0 to $260 \mu \mathrm{m}$ using sieve analysis. Table 4 shows the distribution of the concentrate mineral (scheelite) by particle size and liberation class in terms of mass percentage, which was obtained from the data reported by MLA. Here, the highest mineral 
fractions belong to the medium size and also to highly liberated particles $(5.65 \%)$ and less liberated particles $(0.25 \%)$.

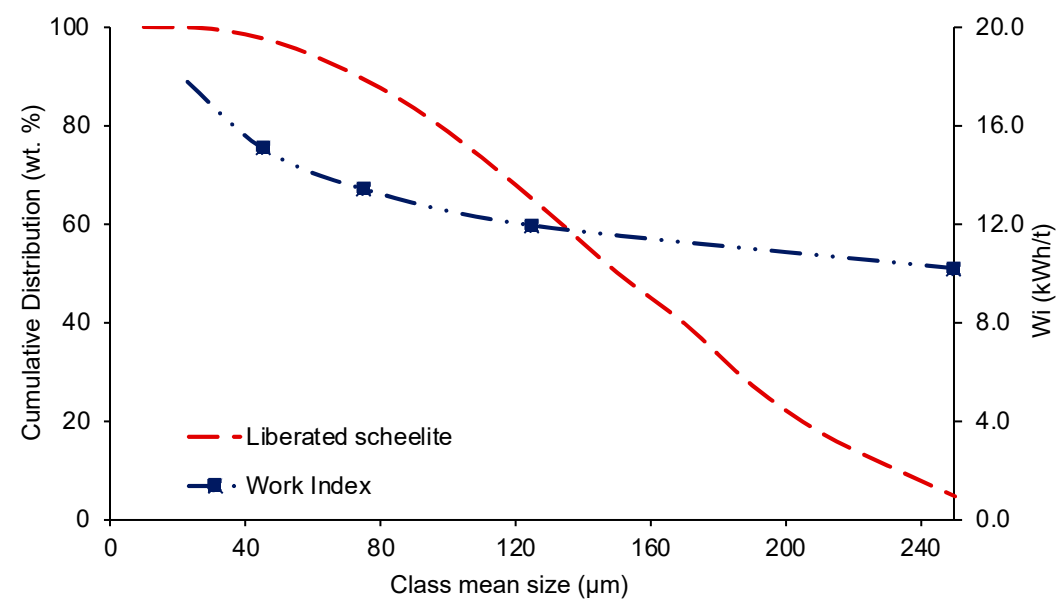

Figure 7. Dependence of the work index on the cumulative distribution of scheelite content in the material.

Figure 8 illustrates how scheelite treatment resulted in a distribution of the ore from the low to high grade of liberation classes in the material. To calculate the distribution density, via simulation, the range of 0-260 $\mu \mathrm{m}$ was divided into particle size segments with intervals of $20 \mu \mathrm{m}$ and liberation grade classes of $>0-10,10-20, \ldots, 90-<100$ and 100 . The differential mass was calculated for each grade/size class (Table 4). In the concentrate, the liberated scheelite is distributed along with the different size classes as shown in Figure 8. The categories presented here are based on the combined fractional area of scheelite, although all particles considered contain one or more scheelite grains.
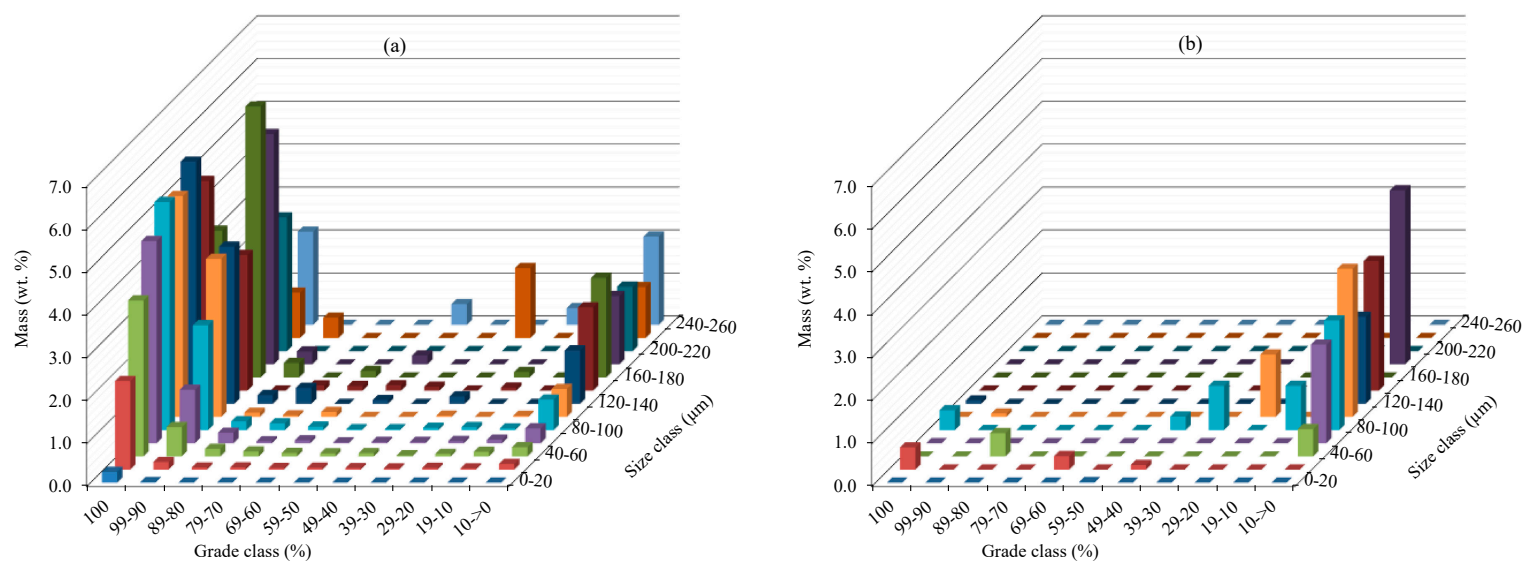

Figure 8. Mineral liberation distribution as a function of particle size with the differential mass and particle grade after comminution and gravity separation. (a) Concentrate and (b) tailings resulting from this separation.

Particles that contain scheelite show a bimodal distribution, with about $14 \%$ of the concentrate in the $>0$ to $10 \%$ of scheelite grade (Figure $8 \mathrm{a}$ ). However, the amount of scheelite in these particles is small, so a low quantity of ore would be obtained if they were liberated. The other accumulation of particles containing scheelite is formed by particles with a scheelite grade higher than $90 \%$, where all of them can be considered as liberated. 
Table 4. Scheelite distribution by particle size and liberation (differential mass).

\begin{tabular}{|c|c|c|c|c|c|c|c|c|c|c|c|c|}
\hline \multirow{2}{*}{$\begin{array}{c}\text { Differential Mass } \\
\text { Size Class }(\mu \mathrm{m})\end{array}$} & \multicolumn{11}{|c|}{ Liberation Class (\%) } & \multirow[b]{2}{*}{ Total } \\
\hline & 100 & $100-90$ & $90-80$ & $80-70$ & $70-60$ & $60-50$ & $50-40$ & $40-30$ & $30-20$ & $20-10$ & $10->0$ & \\
\hline-20 & 0.2523 & 0.0132 & 0.0029 & 0.0013 & 0.0008 & 0.0011 & 0.0016 & 0.0012 & 0.0013 & 0.0018 & 0.0028 & 0.280 \\
\hline $20-40$ & 2.0663 & 0.1761 & 0.0478 & 0.0510 & 0.0357 & 0.0431 & 0.0343 & 0.0262 & 0.0397 & 0.0282 & 0.1312 & 2.680 \\
\hline $40-60$ & 3.6404 & 0.6841 & 0.1784 & 0.1164 & 0.0806 & 0.0723 & 0.0781 & 0.0251 & 0.0610 & 0.1095 & 0.2165 & 5.262 \\
\hline $60-80$ & 4.7151 & 1.2482 & 0.2450 & 0.0466 & 0.0672 & 0.0200 & 0.0327 & 0.0332 & 0.0520 & 0.0808 & 0.3477 & 6.888 \\
\hline 80-100 & 5.3194 & 2.4475 & 0.2051 & 0.1582 & 0.0802 & 0.0207 & 0.0194 & 0.0536 & 0.0708 & 0.0389 & 0.7146 & 9.129 \\
\hline $100-120$ & 5.1505 & 3.6864 & 0.0985 & 0.0369 & 0.1160 & 0.0000 & 0.0000 & 0.0290 & 0.0000 & 0.0252 & 0.6531 & 9.795 \\
\hline $120-140$ & 5.6492 & 3.6631 & 0.2026 & 0.3713 & 0.0000 & 0.0879 & 0.0000 & 0.1721 & 0.0000 & 0.0000 & 1.2448 & 11.391 \\
\hline $140-160$ & 4.8906 & 3.1626 & 0.0000 & 0.1214 & 0.1076 & 0.1263 & 0.0901 & 0.0000 & 0.0708 & 0.0000 & 1.9450 & 10.514 \\
\hline 160-180 & 3.4226 & 6.3199 & 0.3390 & 0.0000 & 0.1530 & 0.0000 & 0.0000 & 0.0000 & 0.1289 & 0.0000 & 2.3243 & 12.688 \\
\hline $180-200$ & 2.0142 & 5.3722 & 0.3014 & 0.0000 & 0.0000 & 0.2080 & 0.0000 & 0.0000 & 0.0000 & 0.1427 & 1.5944 & 9.633 \\
\hline $200-220$ & 2.1339 & 3.1198 & 0.0000 & 0.0000 & 0.0000 & 0.0000 & 0.0000 & 0.0000 & 0.0000 & 0.0000 & 1.5034 & 6.757 \\
\hline $220-240$ & 3.8020 & 1.0597 & 0.4747 & 0.0000 & 0.0000 & 0.0000 & 0.0000 & 1.6339 & 0.0000 & 0.2655 & 1.1875 & 8.423 \\
\hline $240-260$ & 1.4555 & 2.1710 & 0.0000 & 0.0000 & 0.0000 & 0.4848 & 0.0000 & 0.0000 & 0.3913 & 0.0000 & 2.0561 & 6.559 \\
\hline Total & 44.512 & 33.124 & 2.095 & 0.903 & 0.641 & 1.064 & 0.256 & 1.974 & 0.816 & 0.693 & 13.921 & 100.00 \\
\hline
\end{tabular}


The 3D diagram (Figure 8) indicates that liberated scheelite represents $14 \%$ of the total mass of the concentrate and about $0.13 \%$ of the tailings. It is possible to recover the scheelite phases, with a reasonable efficiency, by the use of gravity concentration.

In order to describe the particle populations with different mineral contents, a distribution function based on the beta distribution was carried out [25].

Equation (6) is used as the basis for the calculation of distribution grades when the distribution linear grades are known [25,27]. Using Equation (6) and the back-calculation technic in MATLAB, other parameters such as $\alpha^{M}$ and $\beta^{M}$ were calculated separately. $n, g, g^{M}, L_{0}$, and $L_{1}$ are experimental data, and they represent the number of particles, average grade, and average grade without $L_{0}$ and $L_{1}$ on their edges, respectively, and $\alpha^{M}$ and $\beta^{M}$ are the beta function parameters.

$$
P(\mathrm{~g})= \begin{cases}0 \leq g<1 & L_{0}+\left(1-L_{0}-L_{1}\right) \frac{1}{\int_{0}^{1} \mathrm{~g}^{\alpha^{M}-1}(1-g)^{\beta^{M}-1} \mathrm{~d} g} \int_{0}^{g} x^{\alpha^{M}-1}(1-x)^{\beta^{M}-1} \mathrm{~d} x \\ g=1 & 1\end{cases}
$$

To complete the liberation distribution shown in Figure 8, Equation (6) and the extent data were used to calculate the linear grade distribution of the scheelite and liberated particles. The modeled values are compared with the measured distributions in Figure 9 for eight size fractions.
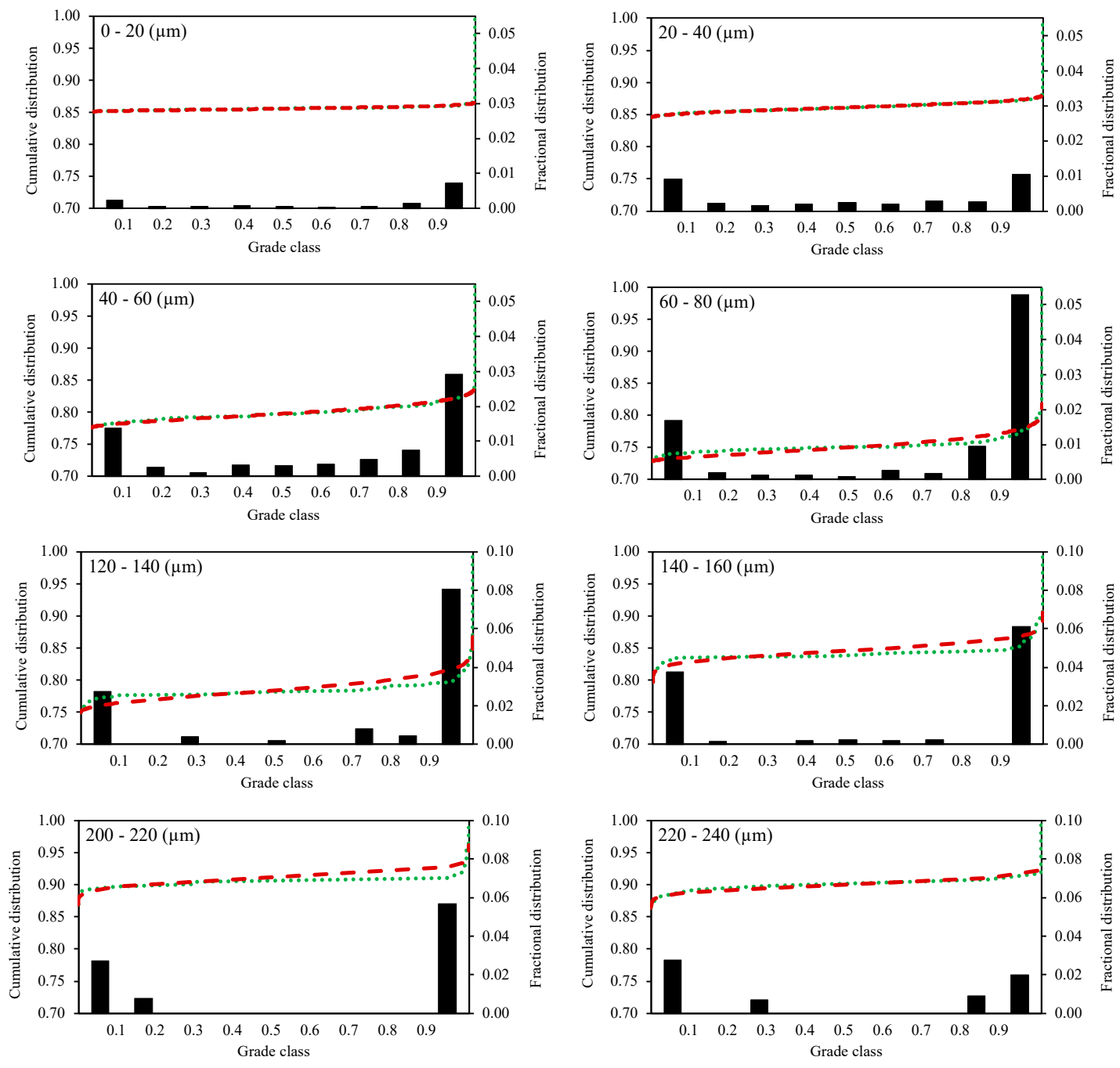

Fractional mass $\quad \ldots .$. Measured data $\quad-$ Simulated model

Figure 9. Cumulative distribution vs. grade class of ore for eight cases in different particle sizes. The difference between the simulated and experimental data is shown. 
The parameters $\alpha$ and $\beta$ of the beta distribution function were calculated using MATLAB and are shown as cumulative distributions (Figure 9). Series of the mineral liberation function equation were calculated based on this extracted data. These included the beta distribution function of scheelite and relative density of each mineral within the sample.

The back-calculated grade distributions must match the measured distributions, giving the experimental data as shown in Figure 9. When the particle size is distinctly smaller than the size of the mineral grains, the tendency for liberated and nearly liberated particles to appear is greatly enhanced, and the beta distribution function reflects this tendency by exhibiting a strong U-shape [25]. This is a good approximation, and it happened in the fine fractions $(0-80 \mu \mathrm{m})$; otherwise, the distribution is bell-shaped. To describe the mineral liberation distribution for different particle sizes, the distribution density of the sample shows that a change from bell-shaped to U-shaped occurred from lower graphs $(120-240 \mu \mathrm{m})$ to upper graphs $(0-80 \mu \mathrm{m})$.

The modeling results are shown in Figure 9 for the scheelite ore, where there is a comparison of the cumulative mass from the experimental data with the simulated data in different size classes. The results show a better fit for the data in some interval sizes than others (e.g., the interval of 140-160 $\mu \mathrm{m})$. In most cases, the curves should superimpose upon each other, if the $\alpha^{M}$ and $\beta^{M}$ values are normalizable. A reasonable agreement is observed for almost all interval sizes, indicating that the calculated liberation could be a good approximation, if that of the cumulative distribution is correct. From Figure 9, it can be also seen that the sample shows a typical behavior as the distribution function does not depend on the particle size. The parameter $g$ was from zero to one.

King [25] has explained that the parameters $\alpha^{M}$ and $\beta^{M}$ define the performance of the distribution, and they can transform the function from bell-shaped to U-shaped. The sample passes from bell-shaped to U-shaped, and the parameters $\alpha^{M}$ and $\beta^{M}$ decrease when the particle size increases (Figure 10 and Table 5).
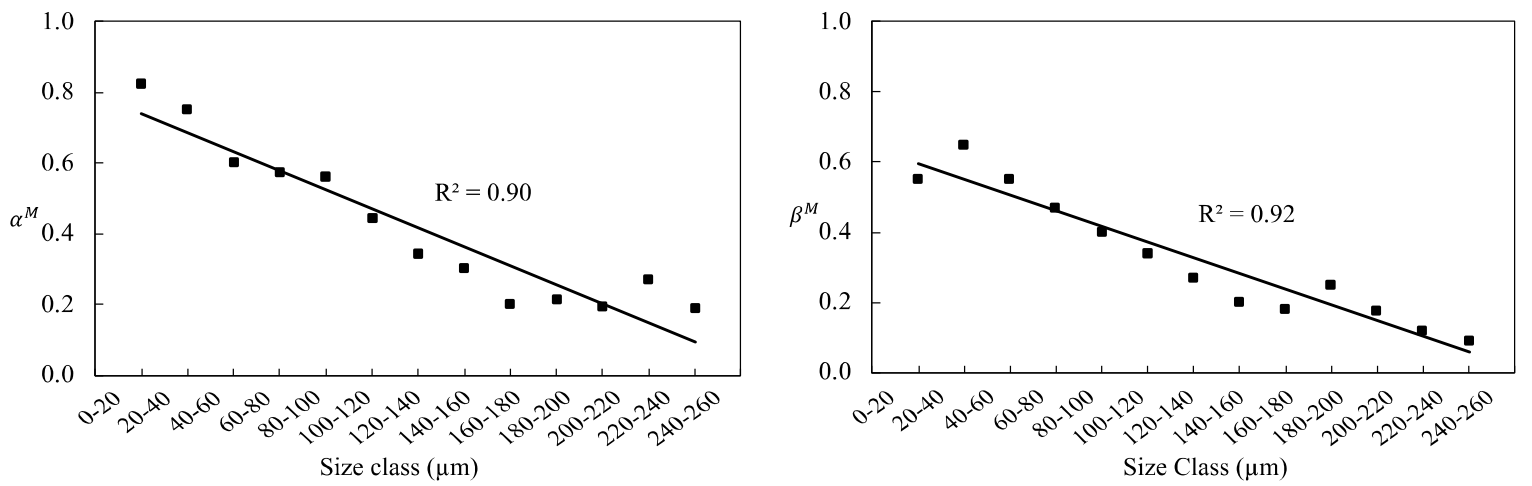

Figure 10. Beta distribution parameters of the ore obtained for a description of the mineral liberation of scheelite.

Table 5. Estimated model parameters for mineral liberation modeling of scheelite.

\begin{tabular}{cccccccccccccccc}
\hline \multicolumn{10}{c}{ Liberation Size Class $(\boldsymbol{\mu m})$} \\
\hline Parameter & $\mathbf{- 2 0}$ & $\mathbf{2 0 - 4 0}$ & $\mathbf{4 0 - 6 0}$ & $\mathbf{6 0 - 8 0}$ & $\mathbf{8 0 - 1 0 0}$ & $\mathbf{1 0 0 - 1 2 0}$ & $\mathbf{1 2 0 - 1 4 0}$ & $\mathbf{1 4 0 - 1 6 0}$ & $\mathbf{1 6 0 - 1 8 0}$ & $\mathbf{1 8 0 - 2 0 0}$ & $\mathbf{2 0 0 - 2 2 0}$ & $\mathbf{2 2 0 - 2 4 0}$ & $\mathbf{2 4 0 - 2 6 0}$ \\
\hline $\boldsymbol{n}$ & 217 & 605 & 356 & 180 & 137 & 94 & 67 & 51 & 50 & 32 & 18 & 10 & 13 \\
$\boldsymbol{\alpha}^{\boldsymbol{M}}$ & 0.82 & 0.75 & 0.60 & 0.57 & 0.56 & 0.44 & 0.34 & 0.30 & 0.20 & 0.21 & 0.19 & 0.27 & 0.19 \\
$\boldsymbol{\beta}^{\boldsymbol{M}}$ & 0.55 & 0.65 & 0.55 & 0.47 & 0.40 & 0.34 & 0.27 & 0.20 & 0.18 & 0.25 & 0.18 & 0.12 & 0.09 \\
\hline
\end{tabular}

This allows the fitting of $\alpha^{M}$ and $\beta^{M}$ values into Equation (6) by the back-calculation technique and hence the calculation of the model parameters. In this case, the parameters $n, g, g^{M}, L_{0}$ and $L_{1}$, and $g$ were determined by fitting Equation (6) to $\alpha^{M}$ and $\beta^{M}$ values for each fraction size using the back-calculation function in MATLAB. This is an optimization procedure that searches for the best combination of parameters that minimizes the error between experimental and simulated $\alpha^{M}$ and $\beta^{M}$ values. 
The variation of distribution function parameters with a constant liberation rate constant was investigated (Table 5), and the results are shown in Figure 10. The values of $\alpha^{M}$ and $\beta^{M}$ seem to satisfy a linear relationship while the liberation rate is constant, with correlation coefficients of 0.90 and 0.92 , respectively. It follows that $\alpha^{M}$ and $\beta^{M}$ values may be predicted from the liberation rate constant as follows:

$$
\begin{aligned}
& \alpha^{M}=-0.05 x+0.79 \\
& \beta^{M}=-0.04 x+0.64
\end{aligned}
$$

The relationship can be further interpreted to show that finer particles are expected for high $\alpha^{\mathrm{M}}$ and $\beta^{\mathrm{M}}$ values. This is in agreement with what is displayed in Figure 9.

\section{Conclusions}

This paper proposes a link between ore characteristics and concentrate feed characterization by particle size and liberation class using a mineral liberation model. An overview of the scheelite liberation modeling results in a procedure to solve the functions, which relates the particle grade and particle size distributions. The liberation results show that $15 \mathrm{wt} . \%$ of the concentrated sample was scheelite and $87 \mathrm{wt} . \%$ of the scheelite was liberated.

Scheelite grains present fine sizes in comparison to most gangue minerals. Their liberation is higher than $45 \%$ in size fractions finer than $120 \mu \mathrm{m}$. Scheelite was liberated at a relatively coarse size fraction (i.e., approx. $80-200 \mu \mathrm{m}$ ), which contains about $71 \%$ of all liberated particles. Higher scheelite grain enrichment is displayed in the size range lower than $106 \mu \mathrm{m}$. The average grain size of scheelite is about $106 \mu \mathrm{m}$, and most parts of the grains have a size smaller than $250 \mu \mathrm{m}$.

The size distribution and the liberation of scheelite allow a good estimation of the mineral distribution in the concentration feed. Suitable agreement between the experimental and simulated data was achieved by using a grain size distribution.

Using the beta distributions, the extent and linear grade distribution of liberated particles were calculated. The calculated values were compared with the measured distributions for eight size fractions.

The work index for the ore deposit ranges from 8.02 to $15.07 \mathrm{kWh} / \mathrm{t}$, indicating a high difference in the energy consumption of the ore in different size fractions. Therefore, a reduction in size would cause an increase in the energy consumption and the cost of comminution.

The behavior of the model parameters for the liberation data in a grinding process can be used in real mineral processing calculations to simulate the possibility for significant improvement in the existing flowsheet with respect to physical separation recovery and grinding efficiency. A liberation model, based on an optimization procedure, was initially developed using the beta distribution function. Finally, the proposed model was confirmed using the beta distribution function and through a comparison of experimental and simulated liberation data.

Author Contributions: Conceptualization, S.A.H., P.A. and J.O.; methodology, S.A.H. and P.A.; software, S.A.H., P.A., M.G.-V. and T.E.; validation, S.A.H., P.A. and J.O.; formal analysis, S.A.H., P.A. and M.G.-V.; investigation, S.A.H., P.A., H.A. and E.G.; resources, J.O.; data curation, S.A.H. and P.A.; writing-original draft preparation, S.A.H. and P.A.; writing-review and editing, S.A.H., P.A., J.O. and C.H.S.; visualization and supervision, J.O. and P.A.; project administration and funding acquisition, J.O.

Funding: This work is based on research supported in part by the OptimOre project. This project has received funding from the European Union's Horizon 2020 research and innovation program under grant agreement No. 642201 and the Consolidated Research Group SGR 444.

Acknowledgments: The authors would like to acknowledge the OptimeOre team for consultation of the results. The Strategic Minerals enterprise helped in the sampling of Penouta. X. Llovet by assisted in the EMPA analyses. Two anonymous reviewers are thanked for helping to improve the manuscript.

Conflicts of Interest: The authors declare no conflict of interest. 


\section{References}

1. European Commission. Study on the Review of the List of Critical Raw Materials; European Commission: Brussels, Belgium, 2017; p. 515. Available online: https://publications.europa.eu/en/publication-detail/-/ publication/08fdab5f-9766-11e7-b92d-01aa75ed71a1/language-en (accessed on 21 April 2018).

2. Mohammadnejad, S.; Noaparast, M.; Hosseini, S.; Aghazadeh, S.; Mousavinezhad, S.; Hosseini, F. Physical methods and flotation practice in the beneficiation of a low grade tungsten-bearing scheelite ore. Russ. J. Non-Ferr. Met. 2018, 59, 6-15. [CrossRef]

3. Rieck, G.D. Tungsten and Its Compounds; Pergamon Press: Norwich, UK, 1967.

4. Ilhan, S.; Kalpakli, A.O.; Kahruman, C.; Yusufoglu, I. The investigation of dissolution behavior of gangue materials during the dissolution of scheelite concentrate in oxalic acid solution. Hydrometallurgy 2013, 136, 15-26. [CrossRef]

5. U.S. Geological Survey. Mineral Commodity Summaries; U.S. Geological Survey: Reston, VA, USA, 2019. [CrossRef]

6. Chakhmouradian, A.R.; Smith, M.P.; Kynicky, J. From "strategic" tungsten to "green" neodymium: A century of critical metals at a glance. Ore Geol. Rev. 2015, 64, 455-458. [CrossRef]

7. Suárez Sánchez, A.; Krzemień, A.; Riesgo Fernández, P.; Iglesias Rodríguez, F.J.; Sánchez Lasheras, F.; de Cos Juez, F.J. Investment in new tungsten mining projects. Resour. Policy 2015, 46, 177-190. [CrossRef]

8. Zhang, J.; Subasinghe, N. Prediction of mineral liberation characteristics of comminuted particles of high-grade ores. Miner. Eng. 2013, 49, 68-76. [CrossRef]

9. Foucaud, Y.; Dehaine, Q.; Filippov, L.O.; Filippova, I.V. Application of falcon centrifuge as a cleaner alternative for complex tungsten ore processing. Minerals 2019, 9, 448. [CrossRef]

10. Lastra, R. Seven practical application cases of liberation analysis. Int. J. Miner. Process. 2007, 84, 337-347. [CrossRef]

11. Fandrich, R.; Gu, Y.; Burrows, D.; Moeller, K. Modern SEM-based mineral liberation analysis. Int. J. Miner. Process. 2007, 84, 310-320. [CrossRef]

12. Fandrich, R.G.; Bearman, R.A.; Boland, J.; Lim, W. Mineral liberation by particle bed breakage. Miner. Eng. 1997, 10, 175-187. [CrossRef]

13. King, R.P.; Schneider, C.L. Mineral liberation and the batch comminution equation. Miner. Eng. 1998, 11, 1143-1160. [CrossRef]

14. Gu, Y. Automated scanning electron microscope based mineral liberation analysis. An introduction to JKMRC/FEI Mineral Liberation Analyser. J. Miner. Mater. Charact. Eng. 2003, 2, 33-41. [CrossRef]

15. Gu, Y.; Schouwstra, R.P.; Rule, C. The value of automated mineralogy. Miner. Eng. 2014, 58, 100-103. [CrossRef]

16. Lassner, E.; Schubert, W. Tungsten: Properties, Chemistry, Technology of the Element, Alloys, and Chemical Compounds; Springer: New York, NY, USA, 1999.

17. Hu, Y.; Gao, Z.; Sun, W.; Liu, X. Anisotropic surface energies and adsorption behaviors of scheelite crystal. Colloid. Surface A 2012, 415, 439-448. [CrossRef]

18. Shepeta, E.D.; Samatova, L.A.; Kondrat'ev, S.A. Kinetics of calcium minerals flotation from scheelite-carbonate ores. J. Min. Sci. 2012, 48, 746-753. [CrossRef]

19. King, R.P. A quantitative model for mineral liberation. J. S. Afr. Inst. Min. Metall. 1975, 76, 170-172.

20. King, R.P. A model for the quantitative estimation of mineral liberation by grinding. Int. J. Miner. Process. 1979, 6, 207-220. [CrossRef]

21. Schaap, W. Illustrated liberation-flotation recovery model for a disseminated mineral in low-grade ore. Trans. Inst. Min. Metall. Section C-Miner. Process. Extr. Metall. 1979, 88, C220-C228.

22. Barbery, G. Mineral Liberation-Measurement, Simulation and Practical Use in Mineral Processing; Quebec Éditions: Montreal, QC, Canada, 1991.

23. Barbery, G.; Leroux, D. Prediction of particle composition distribution after fragmentation of heterogeneous materials. Int. J. Miner. Process. 1988, 22, 9-24. [CrossRef]

24. Subasinghe, G.K.N. The prediction of flotation characteristics of a disseminated ore using ore texture data. In Proceedings of the XXIV International Mineral Processing Congress, Beijing, China, 24-28 September 2008; Wang, D.Z., Sun, C.Y., Wang, F.L., Zhang, L.C., Han, L., Eds.; Science Press: Beijing, China, 2008; pp. 2339-2349. 
25. King, R.P. Modelling and Simulation of Mineral Processing Systems; Society for Mining, Metallurgy, and Exploration, Inc. (SME): Englewood, CO, USA, 2012; pp. 55-96.

26. Zhang, J. Prediction and Influence of Mineral Liberation on Froth Flotation Performance. Ph.D. Thesis, Curtin University, Perth, Australia, 2012; p. 222.

27. Zhang, J.; Subasinghe, N. Development of a flotation model incorporating liberation characteristics. Miner. Eng. 2016, 98, 1-8. [CrossRef]

28. Anticoi, H.; Guasch, E.; Hamid, S.A.; Oliva, J.; Alfonso, P.; Garcia-Valles, M.; Bascompta, M.; Sanmiquel, L.; Escobet, T.; Argelaguet, R.; et al. Breakage Function for HPGR: Mineral and Mechanical Characterization of Tantalum and Tungsten Ores. Minerals 2018, 8, 170. [CrossRef]

29. Gupta, A.; Yan, D.S. Introduction to Mineral Processing Design and Operation; Elsevier: Amsterdam, The Netherlands, 2006; pp. 683-685.

30. Bond, F.C.; Maxson, W.L. Standard grindability tests and calculations. Transactions 1943, 153, 362-373.

31. Magdalinović, N. A procedure for rapid determination of the Bond work index. Int. J. Miner. Process. 1989, 27, 125-132. [CrossRef]

32. Man, Y.T. Why is the Bond Ball Mill Grindability Test done the way it is done? Eur. J. Miner. Process. Environ. Prot. 2002, 2, 34-39.

33. Wikedzi, A.; Arinanda, M.A.; Leißner, T.; Peuker, U.A.; Mütze, T. Breakage and liberation characteristics of low grade sulphide gold ore blends. Miner. Eng. 2018, 115, 33-40. [CrossRef]

34. Bond, F.C. The third theory of comminution. Trans. AIME Min. Eng. 1952, 193, 484-494.

35. Rietveld, H. Line profiles of neutron powder-diffraction peaks for structure refinement. Acta Crystallogr. 1967, 22, 151-152. [CrossRef]

36. Hill, R.J.; Howard, C.J. Quantitative phase analysis from neutron powder diffraction data using the Rietveld method. Appl. Crystallogr. 1987, 20, 467-474. [CrossRef]

37. König, U.; Spicer, E. X-ray diffraction (XRD) as a fast industrial analysis method for heavy mineral sands in process control and automation-Rietveld refinement and data clustering. In The 6th International Heavy Minerals Conference 'Back to Basics'; The Southern African Institute of mining and Metallurgy, Nyala Game Lodge: Natal, South Africa, 2007.

38. Parian, M.; Lamberg, P.; Möckel, R.; Rosenkranz, J. Analysis of mineral grades for geometallurgy: Combined element-to-mineral conversion and quantitative X-ray diffraction. Miner. Eng. 2015, 82, 25-35. [CrossRef]

39. Filippova, I.V.; Filippov, L.O.; Duverger, A.; Severov, V.V. Synergetic effect of a mixture of anionic and nonionic reagents: Ca mineral contrast separation by flotation at neutral pH. Miner. Eng. 2014, 66-68, 135-144. [CrossRef]

40. Rozendaal, A.; le Roux, S.G.; du Plessis, A. Application of microCT scanning in the recovery of endo-skarn associated scheelite from the Riviera Deposit, South Africa. Miner. Eng. 2018, 116, 163-178. [CrossRef] 